\title{
Digestibilidade ileal e perdas endógenas de aminoácidos de dietas com óleo de soja para suínos em crescimento ${ }^{1}$
}

\author{
${ }_{1}$ Parte da tese de Mestrado do primeiro autor apresentada à Universidade Federal de Lavras. \\ 2 Doutoranda em Nutrição de Monogástricos, DZO - UFLA, Lavras - MG. \\ ${ }^{3}$ Departamento de Zootecnia - UFLA, Lavras - MG. \\ 4 Doutor em Nutrição de Monogástricos, DZO - UFLA, Lavras - MG. \\ 5 Pós-doutorando em Nutrição de Monogástricos - DZO - UFLA, Lavras - MG.
}

Erin Caperuto de Almeida ${ }^{2}$, Elias Tadeu Fialho ${ }^{3}$, Vinícius de Souza Cantarelli ${ }^{4}$, Márcio Gilberto Zangeronimo ${ }^{5}$, Renata Apocalypse Nogueira Pereira ${ }^{4}$, Paulo Borges Rodrigues ${ }^{3}$

RESUMO - Este trabalho foi conduzido para avaliar o efeito de diferentes níveis de óleo de soja sobre as perdas endógenas e a digestibilidade ileal aparente e verdadeira dos aminoácidos em dietas para suínos em crescimento. Foram testadas quatro dietas isoprotéicas, à base de milho e farelo de soja, formuladas segundo as exigências para essa fase e suplementadas com níveis crescentes de óleo de soja $(0,0 ; 1,5 ; 3,0 ; 4,5 \%)$ e $0,25 \%$ de óxido crômico como indicador de indigestibilidade. Dezesseis suínos canulados (cânula T simples), com 48,0 $\pm 6,0 \mathrm{~kg}$, foram distribuídos em um delineamento em blocos casualizados, com base no peso dos animais. Não houve efeito dos níveis óleo de soja sobre os coeficientes de digestibilidade ileal aparente de glutamato, glicina, arginina, alanina, prolina, tirosina, histidina e lisina. Observaram-se efeito linear da suplementação com níveis de óleo de soja nos coeficientes de digestibilidade ileal aparente e verdadeira de serina e treonina e efeito quadrático da suplementação de óleo de soja sobre os coeficientes de digestibilidade ileal aparente e verdadeira de valina, fenilalanina, total de aminoácidos não-essenciais e total de aminoácidos essenciais. Os coeficientes de digestibilidade ileal verdadeira de arginina e tirosina também apresentaram efeito quadrático da suplementação de óleo de soja. Melhores valores de digestibilidade ileal aparente e verdadeira dos aminoácidos não-essenciais e essenciais são obtidos com adição de 2,8 a 3,0\% de óleo de soja à dieta de suínos em crescimento.

Palavras-chave: aminoácidos, digestibilidade ileal, metabolismo, nutrição

\section{Ileal digestibility and endogenous losses of amino acids in soybean oil diets to growing pigs}

\begin{abstract}
The present experiment was conducted to evaluate the effect of the different levels of soybean oil on endogenous losses, apparent and true ileal digestibility of amino acids in growing pigs diets. Four isoprotein corn and soybean meal based diets meeting the nutritional requirements for this phase, supplemented with crescent levels of soybean oil, $(0.0$, $1.5,3.0$, and 4.5$)$ were evaluated. Chromic oxide $(0.25 \%)$ was added to serve as digestibility marker. Sixteen cannulated pigs (simple T-cannula), with weight of $48.0 \pm 6.0 \mathrm{~kg}$, were distributed to a complete randomized block design, based in the animal weight. There was no effect of the supplement of soybean oil levels on the apparent ileal digestibility coefficients of glutamate, glycine, arginine, alanine, proline, tyrosine, histidine and lysine. A linear effect was observed with the supplementation of soybean oil levels to the true and apparent ileal digestibility coefficient of threonine and serine and a quadratic effect on the true and apparent ileal digestibility coefficients of valine, phenylalanine, total of non-essential amino acids and total of essential amino acids. True ileal digestibility coefficients of arginine and tyrosine, also showed quadratic effect of soybean oil supplementation. Better values of true and apparent ileal digestibility of essential and nonessential amino acids are obtained with the addition of 2.8 to $3.0 \%$ of soybean oil to diets for growing pigs.
\end{abstract}

Key Words: amino acids, ileal digestibility, metabolism, nutrition

\section{Introdução}

Os recentes avanços da seleção genética na suinocultura têm propiciado a obtenção de animais com maior capacidade para ganho de peso com menor consumo. Dessa forma, a formulação de dietas de alta densidade nutricional e alta digestibilidade tem sido alvo de inúmeras pesquisas. Neste sentido, a utilização de óleos nas dietas, além de excelente fonte calórica, tem sido associada a diversos fatores, como melhora da palatabilidade e redução da pulverulência da dieta, além de valor extracalórico, o quefavorece a digestão e a absorção dos nutrientes não-lipídicos. 
Estudos com suínos em crescimento-terminação comprovaram melhoria na digestibilidade ileal aparente dos aminoácidos quando o nível de óleo de canola na dieta foi aumentado de 2 para 10\% (Imbeah \& Sauer, 1991). Segundo esses autores, a presença de lipídeos no duodeno estimula a produção de colecistocinina, liberada por células enteroendócrinas da mucosa intestinal, estimulando a produção de bile e suco pancreático pelo fígado e pâncreas, respectivamente. Com o aumento da secreção de suco pancreático, a quantidade de enzimas digestivas no intestino delgado torna-se maior, o que, associado ao fato de os lipídeos reduzirem a taxa de esvaziamento gástrico, pode possibilitar maior digestibilidade dos nutrientes da dieta, especialmente as proteínas.

Albin et al. (2000), estudando a inclusão de 0, 10 e 20\% de óleos de soja e de palma nas dietas, observaram aumento da digestibilidade ileal de serina, histidina, arginina, tirosina e leucina com adição de 10 e $20 \%$ de óleo e melhora da digestibilidade de arginina e leucina quando o óleo foi adicionado na proporção de $20 \%$ da dieta. Com óleo de palma, apenas as digestibilidades ileais de serina, histidina, arginina e fenilalanina melhoraram quando adicionado o maior nível desse óleo na dieta.

Li \& Sauer (1994) também notaram melhora na digestibilidade ileal de aminoácidos ao acrescentarem óleo de canola às dietas de leitões desmamados. Neste trabalho, houve diferença no aumento da digestibilidade ileal aparente de $1,4 \%$ para arginina, $3,6 \%$ para treonina, $1,0 \%$ para a serina e 5,6\% para glicina. Resultados similares com suínos em crescimento também foram obtidos por Knabe et al. (1989) e Sauer et al. (1991).

O aumento das perdas endógenas, fundamental para determinação da digestibilidade ileal verdadeira dos aminoácidos, também pode ser influenciado pelos níveis de óleo na dieta. Segundo Pozza et al. (2000), 59\% do nitrogênio endógeno é composto de aminoácidos não-essenciais quando utilizado $1,7 \%$ de óleo de soja em dieta isenta de proteína. Por outro lado, Thiré (1986), utilizando uma dieta isenta de proteína e com $3,0 \%$ de óleo de soja, encontrou $67,3 \%$ de aminoácidos não-essenciais.

Com base nestas informações, realizou-se esta pesquisa com o objetivo de avaliar a digestibilidade ileal aparente e verdadeira dos aminoácidos e as perdas endógenas em dietas suplementadas com até $4,5 \%$ de óleo de soja para suínos em crescimento.

\section{Material e Métodos}

O experimento foi conduzido no Setor de Suinocultura do Departamento de Zootecnia da Universidade Federal de
Lavras, em Lavras - MG. Foram utilizados 16 suínos mestiços (Landrace x Large White), machos castrados com 48,0 $\pm 6,0 \mathrm{~kg}$, previamente canulados (cânula T simples) segundo a técnica adaptada de Li et al. (1994), alojados em baias de alvenaria com comedouros semi-automáticos e bebedouros tipo chupeta.

O delineamento experimental foi em blocos casualizados, com quatro tratamentos e quatro repetições, em que a unidade experimental foi constituída de um animal.

Foram testadas quatro dietas isoprotéicas para suínos em crescimento, à base de milho e farelo de soja, formuladas segundo Rostagno et al (2000), com níveis crescentes de óleo de soja: $0 ; 1,5 ; 3,0$ e 4,5\% (Tabela 1). O período experimental teve duração de quatro dias, três de adaptação às dietas e um de coleta da digesta ileal, realizada durante 24 horas, sem interrupção.

As dietas foram fornecidas umedecidas (1:1) às $8 \mathrm{e}$ às $16 \mathrm{~h}$ e o consumo foi determinado em relação ao peso metabólico ( $\left.\mathrm{PV}^{0,75}\right)$. Em todas as dietas, foi adicionado $0,25 \%$ de óxido crômico $\left(\mathrm{Cr}_{2} \mathrm{O}_{3}\right)$ como indicador da indigestibilidade dos nutrientes. Após a coleta, o volume total de digesta foi homogeneizado e congelado para posterior liofilização e análise laboratorial de acordo com a metodologia descrita pela AOAC (1990).

Foram determinados os valores de digestibilidade ileal aparente dos aminoácidos, calculados com base nos níveis de cromo ( $\mathrm{Cr}$ ) nas dietas e nas digestas, por meio do cálculo do fator de indigestibilidade (FI) e do coeficiente de digestibilidade aparente dos aminoácidos (CDA\%):

$$
\begin{gathered}
\mathrm{FI}=\left[\frac{\mathrm{Cr}_{2} \mathrm{O}_{3} / \text { g nadieta }}{\mathrm{Cr}_{2} \mathrm{O}_{3} \text { /g nadigestaileal }}\right] \\
\mathrm{CDA}(\%)=\left[\frac{\mathrm{mg} \mathrm{AA} / \text { gdieta }-\mathrm{mg} \mathrm{AA} / \mathrm{gE} 1 \mathrm{x} \mathrm{FI}}{\mathrm{mg} \mathrm{AA} / \text { gdieta }}\right] \times 100
\end{gathered}
$$

em que $\mathrm{E}_{1}=$ digesta da dieta testada.

Posteriormente, os mesmos animais foram alimentados com quatro dietas experimentais isentas de proteínas (DIP), com níveis crescentes de óleo de soja, 0; 1,5; 3,0 e $4,5 \%$ (Tabela 2), para quantificação das perdas endógenas e cálculo de digestibilidade ileal verdadeira. A metodologia de arraçoamento e coleta das digestas foi a mesma utilizada no experimento anterior. Foram determinados os valores de digestibilidade ileal verdadeira dos aminoácidos, calculados com base nos níveis de cromo $(\mathrm{Cr})$ nas dietas e nas digestas, pelo cálculo do fator de indigestibilidade (FI) e do coeficiente de digestibilidade verdadeira dos aminoácidos (CDV\%): 
Tabela 1 - Composição centesimal das dietas experimentais Table 1 - Percentage composition of the experimental diets

\begin{tabular}{lrrrr}
\hline $\begin{array}{l}\text { Ingrediente } \\
\text { Ingredient }\end{array}$ & \multicolumn{4}{c}{$\begin{array}{c}\text { Nível de óleo (\%) } \\
\text { Oil level }\end{array}$} \\
\cline { 2 - 5 } & 0,0 & 1,5 & 3,0 & 4,5 \\
\hline Milho moído (Ground corn) & 65,45 & 65,45 & 65,45 & 65,45 \\
Farelo de soja (Soybean meal) & 27,00 & 27,00 & 27,00 & 27,00 \\
Óleo de soja (Soybean oil) & - & 1,50 & 3,00 & 4,50 \\
Fosfato bicálcico (Dicalcium phosphate) & 1,40 & 1,40 & 1,40 & 1,40 \\
Calcário (Limestone) & 0,80 & 0,80 & 0,80 & 0,80 \\
Sal(Salt) & 0,40 & 0,40 & 0,40 & 0,40 \\
Px. vitamínico' (Vitamin premix) & 0,10 & 0,10 & 0,10 & 0,10 \\
Px. mineral ${ }^{2}$ (Mineral premix) & 0,10 & 0,10 & 0,10 & 0,10 \\
Óxido de cromo (Chromium oxide) & 0,25 & 0,25 & 0,25 & 0,25 \\
Caulim (Caulin) & 4,50 & 3,00 & 1,50 & - \\
\hline
\end{tabular}

Composição calculada ${ }^{3}$

Calculated composition

\begin{tabular}{lcccc}
\hline PB $(C P)(\%)$ & 17,89 & 17,89 & 17,89 & 17,89 \\
ED $(D E)(\mathrm{kcal} / \mathrm{kg})$ & 3.198 & 3.325 & 3.452 & 3.579 \\
EE $(\%)$ & 2,63 & 4,11 & 5,6 & 7,08 \\
Lisina total (Total lysine) & 0,91 & 0,91 & 0,91 & 0,91 \\
Treonina (\%) (Threonine) & 0,69 & 0,69 & 0,69 & 0,69 \\
Ca (\%) & 0,76 & 0,76 & 0,76 & 0,76 \\
P disponível (\%) (Available P) & 0,36 & 0,36 & 0,36 & 0,36 \\
\hline
\end{tabular}

1 Px. vitamínico: vit. A - 8.000.000 UI; vit. D -1.200 .000 UI; vit. E - 20.000 $\mathrm{mg}$; vit. $\mathrm{K}_{3}-2500 \mathrm{mg}$; vit. $\mathrm{B}_{12}-20.000 \mathrm{mg} ; \mathrm{B}_{1}-1.000 \mathrm{mg} ; \mathrm{B}_{2}-4.000 \mathrm{mg}$; $\mathrm{B}_{6}-2.000 \mathrm{mg}$; niacina (niacin) $-25.000 \mathrm{mg}$; ác. pantotênico (patothenicacid) $10.000 \mathrm{mg}$; biotina (biotin) $50 \mathrm{mg}$; ác. fólico (folic acid) - $600 \mathrm{mg}$; antioxidante (antioxidant) $125 \mathrm{mg} / \mathrm{kg}$ de produto.

2 Px. mineral: Cu 30.000 mg; Zn - 160.000 mg; I - 1.900 mg; Fe - 100.000 mg;

$\mathrm{Mn}-70.000 \mathrm{mg} ; \mathrm{Se}-500 \mathrm{mg}$, Co $-500 \mathrm{mg} / \mathrm{kg}$ de produto.

3 Valores calculados com base no Rostagno et al. (2000).

${ }^{3}$ Calculated values based on Rostagno et al. (2000).

$$
\operatorname{CDV}(\%)=\left[\frac{\text { mg AA/gdieta }- \text { mg A A/gE1x FI+PE }}{\text { mg AA/gdieta }}\right] \times 100
$$

em que: $\mathrm{E} 1$ = digesta da dieta testada $; \mathrm{PE}=$ perda endógena

As composições de aminoácidos das dietas e das digestas foram determinadas no Laboratório de Pesquisa Animal do DZO/UFLA, por meio de cromatografia líquida de alta eficiência utilizando-se aparelho $\operatorname{Varian}^{\circledR}$, série 9000, segundo metodologia descrita por Lara (2006).

Foram avaliados o coeficiente de digestibilidade ileal aparente e verdadeira e as perdas endógenas de glutamato, serina, glicina, arginina, alanina, prolina, tirosina, histidina, treonina, valina, fenilalanina, lisina, aminoácidos não-essenciais e aminoácidos essenciais analisados.

Os dados referentes aos tratamentos foram submetidos à análise de variância pelo pacote estatístico SISVAR (Sis tema para Análise de Variância de Dados Balanceados), desenvolvido por Ferreira (2000).
Tabela 2 - Composição centesimal das dietas experimentais isentas de proteína

Table 2 - Percentage composition of the free protein experimental diets

\begin{tabular}{|c|c|c|c|c|}
\hline \multirow[t]{2}{*}{$\begin{array}{l}\text { Ingrediente } \\
\text { Ingredient }\end{array}$} & \multicolumn{4}{|c|}{$\begin{array}{c}\text { Nível de óleo (\%) } \\
\text { Oil level }\end{array}$} \\
\hline & 0,0 & 1,5 & 3,0 & 4,5 \\
\hline Açúcar (Sugar) & 39,00 & 39,00 & 39,00 & $39,0($ \\
\hline Amido (Starch) & 45,00 & 45,00 & 45,00 & 45,00 \\
\hline Casca de arroz (Rice hulls) & 8,00 & 8,00 & 8,00 & 8,00 \\
\hline Óleo de soja (Soybean oil) & - & 1,50 & 3,00 & 4,50 \\
\hline Fosfato bicálcico (Dicalcium phosphate) & 1,90 & 1,90 & 1,90 & 1,90 \\
\hline Calcário (Limestone) & 0,75 & 0,75 & 0,75 & 0,75 \\
\hline $\operatorname{Sal}($ Salt $)$ & 0,40 & 0,40 & 0,40 & 0,40 \\
\hline Premix vitamínico ${ }^{1}$ (Vitamin premix) & 0,10 & 0,10 & 0,10 & 0,1 \\
\hline Premix mineral ${ }^{2}$ (Mineral premix) & 0,10 & 0,10 & 0,10 & 0,1 \\
\hline Óxido de cromo (Chromium oxide) & 0,25 & 0,25 & 0,25 & 0,2 \\
\hline Caulim (Caulin) & 4,50 & 3,00 & 1,50 & - \\
\hline
\end{tabular}

Composição calculada ${ }^{3}$

Calculated composition

\begin{tabular}{lrrrr}
\hline PB $(C P)(\%)$ & 0,28 & 0,28 & 0,28 & 0,28 \\
ED $(D E)(\mathrm{kcal} / \mathrm{kg})$ & 3.211 & 3.338 & 3.465 & 3.592 \\
EE $(\%)$ & 0,08 & 1,56 & 3,05 & 4,53 \\
Ca (\%) & 0,76 & 0,76 & 0,76 & 0,76 \\
P disponível (\%) (Available P) & 0,36 & 0,36 & 0,36 & 0,36 \\
\hline
\end{tabular}

1 Premix vitamínico (vitaminin premix): vit. A - $8.000 .000 \mathrm{UI}$; vit. $\mathrm{D}_{3}-1.200 .000 \mathrm{UI}$; vit. $\mathrm{E}-20.000 \mathrm{mg}$; vit. $\mathrm{K}_{3}-2.500 \mathrm{mg}$; vit. $\mathrm{B}_{12}-20.000 \mathrm{mg} ; \mathrm{B}_{1}-1.000 \mathrm{mg}$; $\mathrm{B}_{2}-4.000 \mathrm{mg}$; $\mathrm{B}_{6} 2.000 \mathrm{mg}$; niacina (niacin) $-25.000 \mathrm{mg}$; ác. pantoténico (patothenic acid)- $10.000 \mathrm{mg}$; biotina(biotin) - $50 \mathrm{mg}$; ac. fólico (folic acid) - 600 $\mathrm{mg}$; antioxidante (antioxidant) - $125 \mathrm{mg} / \mathrm{kg}$ de produto.

2 Premix mineral (mineral premix): Cu - $30.000 \mathrm{mg} ; \mathrm{Zn}-160.000 \mathrm{mg} ; \mathrm{I}-1.900 \mathrm{mg}$; $\mathrm{Fe}-100.000 \mathrm{mg} ; \mathrm{Mn}-70.000 \mathrm{mg}$; Se $-500 \mathrm{mg}$, Co $-500 \mathrm{mg} / \mathrm{kg}$ de produto.

3 Valores calculados com base no Rostagno et al. (2000).

Calculated values based on Rostagno et al. (2000).

\section{Resultados e Discussão}

A composição aminoacídica das dietas encontra-se na Tabela 3 e os coeficientes de digestibilidade ileal aparente dos aminoácidos, na Tabela 4.

O coeficiente de digestibilidade ileal aparente de histidina e lisina não diferiu $(\mathrm{P}>0,05)$ entre os níveis de óleo de soja utilizados. No entanto, Li \& Sauer (1994) observaram melhora de $3,2 \%$ na digestibilidade de lisinaquando aumentaram de 3,2 para 9,2\% o nível de óleo de canola na dieta. Segundo esses autores, o tipo de óleo também pode influencia r a digestibilidade dos nutrientes, o que depende de sua composição lipídica. Esses resultados foram semelhantes aos obtidos por Imbeah \& Sauer (1991) com o mesmo nível de óleo na dieta. No entanto, esses autores não notaram diferenças $(\mathrm{P}>0,05)$ na digestibilidade ileal dos aminoácidos quando utilizaram níveis de 2,0 e 6,0\% de inclusão na dieta.

Houve efeito quadrático $(\mathrm{P}<0,05)$ dos níveis de óleo na dieta sobre a digestibilidade dos aminoácidos essenciais 
Tabela 3 - Composição de aminoácidos das $\operatorname{dietas}^{1}$ (\%MS) Table 3 - Composition of amino acid of the diets (\%DM)

\begin{tabular}{lcc}
\hline Aminoácido & \multicolumn{2}{c}{$\begin{array}{c}\text { Dieta } \\
\text { Diet }\end{array}$} \\
\cline { 2 - 3 } & $\begin{array}{c}\text { Milho }+ \\
\text { farelo de soja } \\
\text { Corn }+\end{array}$ & $\begin{array}{c}\text { Dieta isenta } \\
\text { de proteína } \\
\text { Free protein }\end{array}$ \\
& soybean meal & diet \\
\hline Glutamato (Glutamic acid) & 0,94 & 0,041 \\
Serina (Serine) & 0,47 & 0,005 \\
Glicina (Glycine) & 0,74 & 0,005 \\
Histidina (Histidine) & 0,59 & 0,000 \\
Arginina (Arginine) & 1,46 & 0,018 \\
Treonina (Threonine) & 0,67 & 0,008 \\
Alanina (Alanine) & 0,75 & 0,019 \\
Prolina (Proline) & 1,68 & 0,003 \\
Tirosina (Tyrosine) & 0,63 & 0,011 \\
Valina (Valine) & 0,50 & 0,006 \\
Fenilalanina (Phenylalanine) & 0,70 & 0,011 \\
Lisina (Lysine) & 0,76 & 0,011 \\
Aminoácidos totais (Total amino acids) & 9,865 & 0,138 \\
\hline 1 Determinado no Laboratório de Pesquisa Animal do DZO/UFLA, por meio \\
de cromatografia líquida de alta eficiência utilizando-se aparelho Varian \\
série 9000. & & \\
1 Determined in theLaboratório de Pesquisa Animal do DZO/UFLA, using high performance \\
liquid chromatography Varian ${ }^{\circledR}$ (9000 serie). & \\
\hline
\end{tabular}

(Figura 1). Até o nível de 2,9\% de inclusão de óleo, houve aumento na digestibilidade dos aminoácidos essenciais, seguido de redução a partir desse nível. Esses resultados contrariam os encontrados por Li \& Sauer (1994) e Imbeah

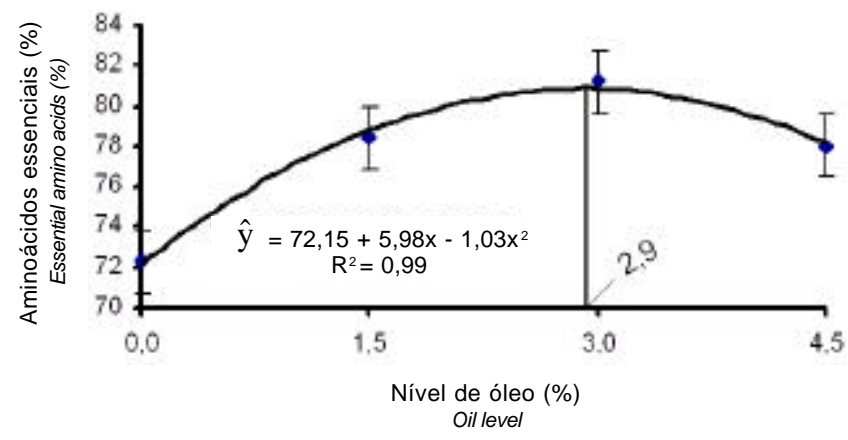

Figura 1 - Efeito dos níveis de óleo sobre o coeficiente de digestibilidade ileal aparente dos aminoácidos essenciais.

Figure 1 - Effect of oil levels on apparent ileal digestibility coefficient of the essential amino acids.

Tabela 4 - Coeficientes de digestibilidade ileal aparente dos aminoácidos (\%), em função dos níveis de óleo

Table 4 - Apparent ileal digestibility coefficient of the amino acids (\%) related to oil levels

\begin{tabular}{|c|c|c|c|c|c|c|c|c|}
\hline \multirow[t]{2}{*}{$\begin{array}{l}\text { Aminoácido } \\
\text { Amino acid }\end{array}$} & \multicolumn{4}{|c|}{$\begin{array}{c}\text { Nível de óleo }(\%) \\
\text { Oil level }\end{array}$} & \multirow[t]{2}{*}{$\begin{array}{l}\text { Equação } \\
\text { Equation }\end{array}$} & \multirow[b]{2}{*}{$\mathrm{R}^{2}$} & \multirow[b]{2}{*}{$\mathrm{EPM}^{1}$} & \multirow[b]{2}{*}{$\mathrm{CV}(\%)$} \\
\hline & 0,0 & 1,5 & 3,0 & 4,5 & & & & \\
\hline $\begin{array}{l}\text { Essencial }^{2} \\
\text { Essential }\end{array}$ & 72,29 & 78,42 & 81,20 & 78,04 & $\hat{y}=72,16+5,98 x-1,03 \times 2$ & 99,94 & 1,58 & 4,09 \\
\hline $\begin{array}{l}\text { Essential } \\
\text { Não essencial } \\
\text { Non-essential }\end{array}$ & 71,62 & 79,82 & 81,78 & 79,77 & $\hat{y}=71,73+6,87 x-1,14 x 2$ & 95,51 & 1,49 & 3,81 \\
\hline $\begin{array}{l}\text { Lisina } \\
\text { Lysine }\end{array}$ & 78,31 & 73,16 & 79,51 & 76,30 & - & NS & 3,07 & 8,0 \\
\hline Treonina $^{3}$ & 56,11 & 66,05 & 71,00 & 79,90 & $\hat{y}=5,09 x+56,82$ & 94,87 & 3,64 & 10,66 \\
\hline $\begin{array}{l}\text { Threonine } \\
\text { Histidina } \\
\text { Histidine }\end{array}$ & 70,12 & 74,28 & 75,46 & 72,97 & - & NS & 7,76 & 21,22 \\
\hline $\begin{array}{l}\text { Valina }^{2} \\
\text { Valine }\end{array}$ & 74,28 & 91,49 & 90,09 & 82,40 & $\hat{y}=74,90+13,98 x-2,77 \times 2$ & 90,27 & 4,23 & 10,00 \\
\hline Fenilalanina $^{2}$ & 82,61 & 87,11 & 89,96 & 78,61 & $\hat{y}=81,98+7,32 x-1,76 \times 2$ & 94,39 & 2,84 & 6,71 \\
\hline $\begin{array}{l}\text { Phenylalanine } \\
\text { Arginina }^{2} \\
\text { Arginine }\end{array}$ & 90,37 & 92,48 & 94,91 & 92,35 & - & 98,13 & 2,28 & 4,93 \\
\hline $\begin{array}{l}\text { Serina } \\
\text { Serine }\end{array}$ & 46,67 & 75,81 & 72,82 & 79,03 & $\hat{y}=54,47+6,27 x$ & 65,02 & 7,90 & 23,04 \\
\hline Glicina & 65,82 & 76,62 & 78,04 & 78,09 & - & NS & 7,43 & 19,91 \\
\hline $\begin{array}{l}\text { Glycine } \\
\text { Prolina } \\
\text { Proline }\end{array}$ & 94,71 & 95,98 & 96,68 & 95,56 & - & NS & 1,51 & 3,16 \\
\hline $\begin{array}{l}\text { Tirosina } \\
\text { Tyrosine }\end{array}$ & 74,10 & 80,33 & 89,31 & 71,19 & - & 95,92 & 5,91 & 15,00 \\
\hline Alanina & 81,59 & 86,62 & 87,06 & 84,82 & - & NS & 3,04 & 7,15 \\
\hline $\begin{array}{l}\text { Alanine } \\
\text { Glutamato } \\
\text { Glutamic acid }\end{array}$ & 48,10 & 50,93 & 53,67 & 57,37 & - & NS & 7,36 & 28,05 \\
\hline
\end{tabular}

1 Erro-padrão da média (Standard mean error).

2 Efeito quadrático $(P<0,05)$ (Quadratic effect, $P<0.05)$

${ }^{3}$ Efeito linear $(P<0,05)$ (Linear effect, $\left.P<0.05\right)$. 
\& Sauer (1991), que observaram aumentos crescentes na digestibilidade dos aminoácidos essenciais ao elevarem os níveis de óleo de canola de 3,2 para $12,2 \%$ e de 2,0 para $10 \%$, respectivamente.

A inclusão de óleo de soja em níveis de até $4,5 \%$ da dieta alterou de forma quadrática $(\mathrm{P}<0,05)$ o coeficiente de digestibilidade ileal aparente do total de aminoácidos nãoessenciais (Figura 2). Nesse caso, houve aumento na digestibilidade desses aminoácidos até o nível de 3,02\% de óleo na dieta. Entretanto, não houve diferenças $(\mathrm{P}>0,05)$ para a maioria dos aminoácidos não-essenciais, o que está de acordo com os resultados descritos por Allee \& Frank (2001), que não observaram aumento na digestibilidade aparente dos aminoácidos não-essenciais quando analisaram separadamente a adição de 2 a $11 \%$ de óleo de milho em dietas para suínos em crescimento. Por outro lado, Li \& Sauer (1994) verificaram efeito linear crescente $(\mathrm{P}<0,05)$ para a maioria dos aminoácidos não-essenciais quando utilizaram óleo de canola. Esses autores notaram aumento nos valores de digestibilidade que variaram de $1,0 \%$ para a serina até $5,6 \%$ para a glicina, quando comparados os níveis de inclusão de óleo de 3,2 até 12,2\%.

A porcentagem de aminoácidos não-essenciais nas perdas endógenas foi de 65 a $70 \%$ nos níveis de óleo estudados (Tabela 5), o que está de acordo com os resultados obtidos por Wünsche et al. (1987), citados por Souffrant (1991), que demonstraram que $65 \%$ do nitrogênio endógeno é composto de aminoácidos não-essenciais. Os valores encontrados neste experimento $(21,41 \%$ de prolina e $13,72 \%$ glicina em relação ao total de aminoácidos) corroboram os

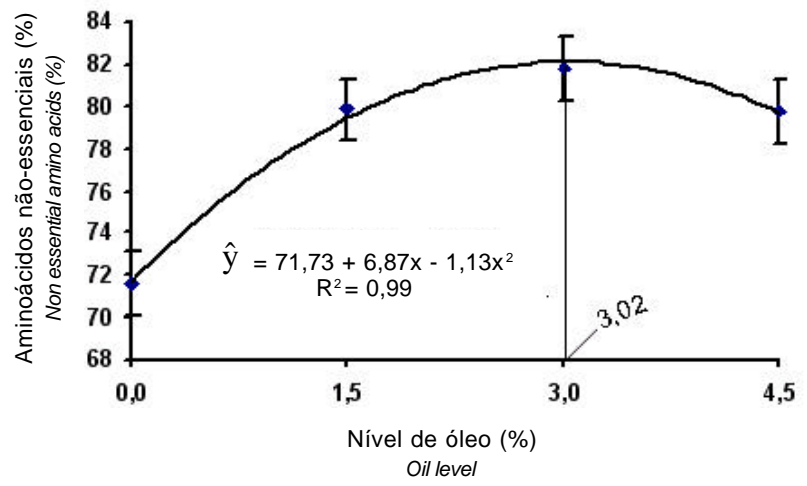

Figura 2 - Efeito dos níveis de óleo sobre o coeficiente de digestibilidade ileal aparente dos aminoácidos nãoessenciais.

Figure 2 - Effect of oil levels on apparent ileal digestibility coefficient of the non essential amino acids.

descritos por esses autores, que também verificaram $25 \%$ do nitrogênio proveniente da prolina e $12 \%$ da glicina.

$\mathrm{O}$ coeficiente de digestibilidade ileal verdadeira dos aminoácidos não-essenciais (Tabela 6) apresentou efeito quadrático $(\mathrm{P}<0,05)$ com o aumento desses valores até o nível de 2,93\% de inclusão de óleo (Figura 3).

Verificou-se efeito quadrático $(\mathrm{P}<0,05)$ dos níveis de óleo na digestibilidade dos aminoácidos essenciais totais, que aumentou até o nível de $2,76 \%$ de inclusão de óleo (Figura 4). No entanto, assim como na digestibilidade ileal aparente, a digestibilidade de alguns aminoácidos, quando avaliados separadamente, apresentou tendências diferenciadas. Os valores de serina e treonina, por exemplo, apresentaram efeito linear crescente $(\mathrm{P}<0,05)$ de melhora

Tabela 5 - Perdas endógenas de aminoácidos (\%MS) e porcentagem do aminoácido em relação ao total de aminoácidos da digesta Table 5 - Endogenous losses of amino acid (\% DM) and amino acid percentage in relation to the amino acid total related to oil supplementation

\begin{tabular}{|c|c|c|c|c|c|c|c|c|}
\hline \multirow[t]{2}{*}{$\begin{array}{l}\text { Aminoácido } \\
\text { Amino acid }\end{array}$} & \multicolumn{8}{|c|}{$\begin{array}{c}\text { Perda endógena } \\
\text { Endogenous loss }\end{array}$} \\
\hline & $0,0 \%$ & $\%$ AAT & $1,5 \%$ & $\%$ AAT & $3,0 \%$ & $\%$ AAT & $4,5 \%$ & $\%$ AAT \\
\hline Glutamato (Glutamic acid) & 1,43 & 6,51 & 4,01 & 7,93 & 1,39 & 3,88 & 3,10 & 9,67 \\
\hline Serina (Serine) & 1,30 & 5,90 & 2,68 & 5,29 & 2,43 & 6,77 & 2,36 & 7,37 \\
\hline Glicina (Glycine) & 3,02 & 13,72 & 2,92 & 5,78 & 3,44 & 9,60 & 2,10 & 6,56 \\
\hline Arginina (Arginine) & 2,33 & 10,59 & 10,59 & 20,94 & 7,41 & 20,68 & 6,16 & 19,22 \\
\hline Alanina (Alanine) & 0,21 & 0,97 & 2,28 & 4,52 & 1,08 & 3,02 & 2,56 & 7,98 \\
\hline Prolina (Proline) & 4,71 & 21,41 & 7,03 & 13,91 & 5,44 & 15,20 & 3,90 & 12,17 \\
\hline Tirosina (Tyrosine) & 1,85 & 8,42 & 5,28 & 10,44 & 2,04 & 5,68 & 2,35 & 7,33 \\
\hline Histidina (Histidine) & 0,71 & 3,21 & 1,14 & 2,25 & 1,00 & 2,80 & 0,86 & 2,67 \\
\hline Treonina (Threonine) & 0,46 & 2,11 & 2,71 & 5,35 & 1,26 & 3,51 & 2,44 & 7,61 \\
\hline Valina (Valine) & 0,64 & 2,91 & 4,62 & 9,15 & 1,82 & 5,08 & 1,35 & 4,21 \\
\hline Fenilalanina (Phenylalanine) & 0,80 & 3,62 & 1,86 & 3,68 & 1,33 & 3,71 & 0,96 & 2,99 \\
\hline Lisina (Lysine) & 4,54 & 20,63 & 5,43 & 10,74 & 7,18 & 20,06 & 3,92 & 12,24 \\
\hline Não essenciais (Non-essential) & 14,84 & 67,52 & 34,79 & 68,82 & 23,22 & 64,84 & 22,51 & 70,29 \\
\hline Essenciais (Essential) & 7,14 & 32,48 & 15,76 & 31,18 & 12,59 & 35,16 & 9,52 & 29,71 \\
\hline AAT & 21,98 & 100 & 50,55 & 100 & 35,81 & 100 & 32,03 & 100 \\
\hline
\end{tabular}

AAT = Aminoácidos totais analisados (Total amino acid analyzed). 
Tabela 6 - Coeficientes de digestibilidade ileal verdadeira dos aminoácidos (\%)

Table 6 - True ileal digestibility coefficient of the amino acids (\%)

\begin{tabular}{|c|c|c|c|c|c|c|c|c|}
\hline \multirow{2}{*}{$\begin{array}{l}\text { Aminoácido } \\
\text { Amino acid }\end{array}$} & \multicolumn{4}{|c|}{$\begin{array}{c}\text { Nível de óleo }(\%) \\
\text { Oil level }\end{array}$} & \multirow{2}{*}{$\begin{array}{l}\text { Equação } \\
\text { Equation }\end{array}$} & \multirow[b]{2}{*}{$\mathrm{R}^{2}$} & \multirow[b]{2}{*}{$\mathrm{EPM}^{1}$} & \multirow[b]{2}{*}{$\mathrm{CV}(\%)$} \\
\hline & 0,0 & 1,5 & 3,0 & 4,5 & & & & \\
\hline Essencial $^{2}$ & 74,35 & 83,04 & 84,93 & 80,91 & $\hat{y}=74,391+7,795 x-1,41 x^{2}$ & 99,94 & 1,58 & 3,92 \\
\hline $\begin{array}{l}\text { Essential } \\
\text { Não-essencial }{ }^{2} \\
\text { Non-essential }\end{array}$ & 73,86 & 84,80 & 85,05 & 83,32 & $\hat{y}=74,296+8,34 x-1,4078 x^{2}$ & 95,51 & 1,53 & 3,74 \\
\hline $\begin{array}{l}\text { Lisina } \\
\text { Lysine }\end{array}$ & 84,29 & 80,32 & 88,99 & 81,48 & - & NS & 3,07 & 7,33 \\
\hline Treonina ${ }^{3}$ & 56,80 & 70,09 & 72,88 & 83,54 & $\hat{y}=58,38+5,53 x$ & 94,87 & 3,64 & 10,27 \\
\hline $\begin{array}{l}\text { Threonine } \\
\text { Histidina } \\
\text { Histidine }\end{array}$ & 71,32 & 76,22 & 77,17 & 74,43 & - & NS & 7,77 & 20,77 \\
\hline $\begin{array}{l}\text { Valina }^{2} \\
\text { Valine }\end{array}$ & 75,57 & 98,79 & 93,76 & 85,12 & $\hat{y}=76,802+17,504 x-3,540 x^{2}$ & 90,27 & 4,29 & 9,72 \\
\hline Fenilalanina ${ }^{2}$ & 83,74 & 89,77 & 91,85 & 79,98 & $\hat{y}=83,241+8,336 x-1,988 x^{2}$ & 94,39 & 2,84 & 6,57 \\
\hline $\begin{array}{l}\text { Phenylalanine } \\
\text { Arginina }^{2} \\
\text { Arginine }\end{array}$ & 90,37 & 92,48 & 94,91 & 92,35 & $\hat{y}=92,148+5,943 x-1,111 x^{2}$ & 98,13 & 2,25 & 4,65 \\
\hline $\begin{array}{l}\text { Serina }{ }^{3} \\
\text { Serine }\end{array}$ & 49,42 & 81,47 & 77,96 & 84,03 & $\hat{\mathrm{y}}=58,17+6,69 \mathrm{x}$ & 65,02 & 7,90 & 18,92 \\
\hline Glicina & 69,91 & 80,58 & 82,70 & 80,94 & - & NS & 7,43 & 18,92 \\
\hline $\begin{array}{l}\text { Glycine } \\
\text { Prolina } \\
\text { Proline }\end{array}$ & 97,19 & 98,83 & 99,04 & 97,88 & 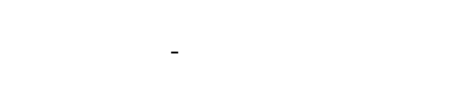 & NS & 1,11 & 2,27 \\
\hline $\begin{array}{l}\text { Tirosina } \\
\text { Tyrosine }\end{array}$ & 77,04 & 88,73 & 92,54 & 74,93 & $\hat{y}=76,362+14,485 x-3,256 x^{2}$ & 95,92 & 5,91 & 14,18 \\
\hline Alanina & 81,88 & 89,69 & 88,51 & 88,24 & - & NS & 3,04 & 6,98 \\
\hline $\begin{array}{l}\text { Alanine } \\
\text { Glutamato } \\
\text { Glutamic acid }\end{array}$ & 49,62 & 55,21 & 55,15 & 60,67 & - & NS & 7,36 & 26,70 \\
\hline
\end{tabular}

1 Erro-padrão da média (Standard mean error)

2 Efeito quadrático $(P<0,05)$ (quadract effect, $P<0.05)$.

${ }^{3}$ Efeito linear $(P<0,05)$ (Linear effect, $\left.P<0.05\right)$.

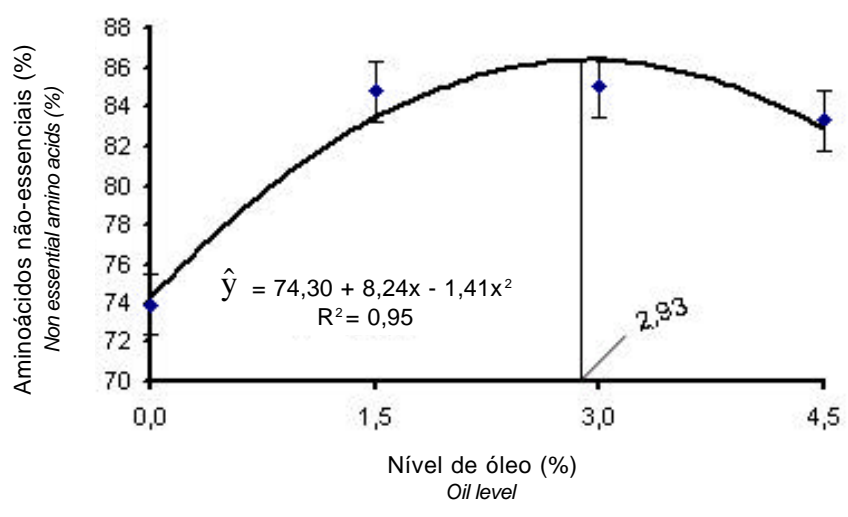

Figura 3 - Efeito dos níveis de óleo sobre o coeficiente de digestibilidade ileal verdadeira dos aminoácidos nãoessenciais.

Figure 3 - Effect of oil levels on true ileal digestibility coefficient of the non-essential amino acids.

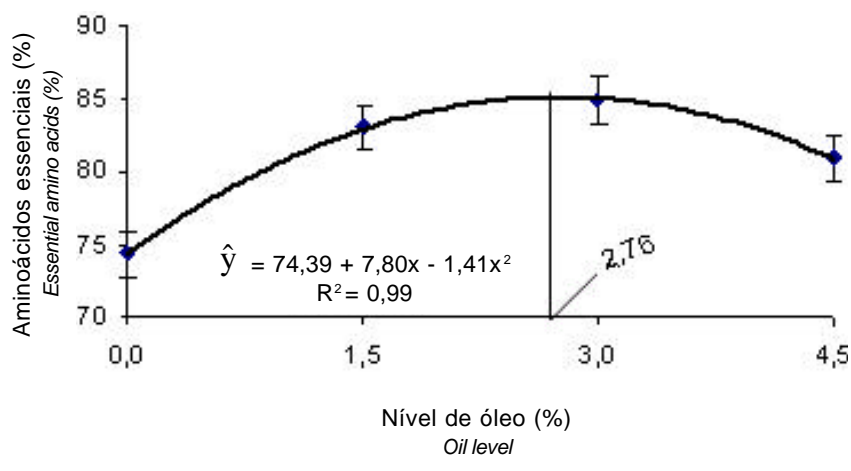

Figura 4 - Efeito dos níveis de óleo sobre o coeficiente de digestibilidade ileal verdadeira dos aminoácidos es senciais.

Figure 4 - Effect of oil levels on true ileal digestibility coefficient of the essential amino acids. 
na digestibilidade conforme aumentaram os níveis de óleo de soja na dieta.

A inclusão de óleo em níveis de até $4,5 \%$ não alterou $(\mathrm{P}>0,05)$ o coeficiente de digestibilidade ileal verdadeira de aminoácidos não-essenciais como glutamato, glicina, alanina e prolina. Os coeficiente de digestibilidade ileal verdadeira dos aminoácidos essenciais histidina e lisina não diferiram $(\mathrm{P}<0,05)$ entre as dietas.

\section{Conclusões}

O óleo de soja interfere na digestibilidade de alguns aminoácidos. A melhor digestibilidade ileal aparente e verdadeira desses aminoácidos em suínos é obtida com adição de 2,8 a $3,0 \%$ de óleo na dieta.

\section{Literatura Citada}

ALBIN, D.M.; SMIRICKY, M.R.; WUBBEN, J.E. et al. The effect of dietary level of soybean oil and palm oil on apparent ileal amino acid digestibility and postprandial flow patterns of chromic oxide and amino acids in pigs. Canadian Journal of Animal Science, p.495-503, 2001.

ALLEE, G.L.; FRANK, J.K. Effect of corn oil on amino acid digestibility of soybean meal. Research Reports from the Nutrient Composition and Carbohydrate Utilization Teams for the Soy/Swine Nutrition Research Program. Illinois: University of Illinois, 2001. p.24-32.

ASSOCIATION OF OFFICIAL ANALYTICAL CHEMISTS - AOAC. Agricultural chemicals, contaminants and drugs. In: Official methods of analysis of the Association of Official Analytical Chemists. 15.ed. Arlington, 1990. v.1. 684p.

FERREIRA, D.F. Sistema de análise de variância para dados balanceados: SISVAR. Lavras: Universidade Federal de Lavras, 2000. (CD-ROM).
IMBEAH, M.; SAUER, W.C. The effect of dietary level of fat on amino acid digestibilities in soybean meal and canola meal and on rate of passage in growing pigs. Livestock Production Science, v.29, p.227, 1991.

KNABE, D.A.; LA RUE, D.C.; GREGG, E.J. et al. Apparent digestibility of nitrogen and amino acids in protein feedstuffs by growing pigs. Journal Science, v.67, p.441, 1989.

LARA, L.B. Biodisponibilidade de aminoácidos em alimentos para papagaios adultos. Lavras: Universidade Federal de Lavras, 2006. 179p. Tese (Doutorado em Zootecnia) Universidade Federal de Lavras, 2006.

LI, S.; SAUER, W.C.; HARTING, R.T. Effect of dietary fiber level on amino acid digestibility in young pigs. Canadian Journal Animal Science, v.74, n.2, p.327-377, 1994.

LI, S.; SAUER, W.C. The effect of dietary fat content on amino acid digestibility in young pigs. Journal of Animal Science, v.72, p.1737-1743, 1994.

POZZA, P.C.; GOMES, P.C.; DONZELE, J.L. et al. Exigência de treonina para leitoas dos 15 aos $30 \mathrm{~kg}$. Revista Brasileira de Zootecnia, vol.29, n.3, p.817-822, 2000.

ROSTAGNO, H.S.; ALBINO, L.F.T.; DONZELE, J.L. et al. Tabelas brasileiras para aves e suínos: composição de alimentos e exigências nutricionais. Viçosa, MG: Editora UFV, 2000. 141p.

SAUER, W.C.; MOSENTHIN, R.; AHRENS, F. et al. The effect of source of fiber on ileal and fecal amino acid digestibility and bacterial nitrogen excretion in growing pigs. Journal of Animal Science, v.69, p.4070, 1991.

SOUFFRANT, W.B. Endogenous nitrogen losses during digestion in pigs. In: VERSTEGEN, M.W.A.; HUISMAN, J.; HARTOG, L.A. (Eds.). Digestive physiology in pigs. Wageningen: Pudoc Wageningen, 1991. p.147.

THIRÉ, M.C. Valores energéticos e digestibilidade ileal e total de aminoácidos em alimentos brasileiros, para suínos. Viçosa, MG: Universidade Federal de Viçosa, 1986. 65p. Dissertação (Mestrado em Zootecnia) - Universidade Federal de Viçosa, 1986.

Recebido: $12 / 06 / 06$ Aprovado: 27/02/07 